\title{
Microbial mediation of watershed biogeochemical cycles
}

\author{
JiLlian F. BANFIELD ${ }^{1,2,4}$, AlEXANDER THOMAS ${ }^{2}$, PAUla \\ MATHEUS CARNEVALI ${ }^{1}$, ADI LAVY ${ }^{1}$, JACOB WEST- \\ ROBERTS $^{2}$, ALEXANDER CRITS-CHRISTOPH ${ }^{3}$, KENNETH \\ HuRST WILLIAMS ${ }^{4}$, SUSAN HuBbarD ${ }^{4}$
}

${ }^{1}$ Department of Earth and Planetary Sciences, Berkeley, CA, USA

${ }^{2}$ Department of Environmental Science, Policy, and Management, Berkeley, CA, USA

${ }^{3}$ Department of Plant and Microbial Biology, University of California, Berkeley, Berkeley, CA, USA

${ }^{4}$ Earth and Environmental Sciences, Lawrence Berkeley National Laboratory, Berkeley, CA, USA

The disparity of scale of encompassed by a watershed as compared to the micron-scale distances over which microorganisms function presents a significant challenge for development of predictive biogeochemically informed models of ecosystem function. Within complex and heterogeneous watershed environments there are consortia of microorganisms whose activities potentially modulate $\mathrm{C}, \mathrm{N}, \mathrm{S}$ and $\mathrm{H}_{2}$ exports. Water that falls on hillslopes interacts with soil and sediment minerals and nutrient stocks prior to riverine discharge. We apply genome-resolved metagenomic methods, coupled to metatranscriptomics, to define microbial consortia along the riparian zone floodplain, across a hillslope to river transect and associated with the four major vegetation types of the mountainous East River Watershed in Colorado. Community structure changes with distance from the floodplain and from the shale bedrock. Vegetation type and watershed position exert relatively minor controls on soil consortia, yet community membership, methylamine degradation and nitrogen assimilation distinguish conifer from aspen, sagebush and meadow soils, which are dominated by autotrophic ammonia oxidation. We have defined a core floodplain microbiome and documented commonalities in community composition and metabolic potential, based on analysis of three distinct meanderassociated floodplains. The core floodplain microbiome is enriched in bacterial capacities for aerobic respiration, aerobic oxidation of $\mathrm{CO}$ and other small molecules and thiosulfate oxidation with formation of elemental sulfur. The findings generally support a functional zonation approach to predicting microbial impacts on watershed biogeochemistry. 